\title{
Mystery shopping in psychiatric service evaluation - ethical issues
}

\author{
Tom Walker, ${ }^{1}$ Sanju George ${ }^{2}$
}

The Psychiatrist (2010), 34, 121-122, doi: 10.1192/pb.bp.109.027821

${ }^{1}$ Keele University: ${ }^{2}$ Birmingham and Solihull Mental Health NHS Foundation Trust

Correspondence to Sanju George (sanju.george@bsmhft.nhs.uk)
Summary Mystery shopping is being increasingly used in psychiatric service evaluation but because it involves an element of deception, akin to research involving pseudo-patients, questions have been raised about its ethical acceptability. Here we discuss these ethical issues and argue that mystery shopping should only take place subject to certain conditions. First, it ought to be clear that the evaluation cannot be done by using non-deceptive methods. Second, independent scrutiny should conclude that the importance of the aims of the evaluation is sufficient to justify the deception used.

Declaration of interest S.G. is an expert panel member of Birmingham and Solihull research ethics committee, and T.W. is a member of Keele University's ethics review panel.
Mystery shopping, where people pretend to be clients in order to assess the quality of service or obtain specific information for research purposes, has long been a valuable tool for evaluating service provision in the business world, particularly in retail services. More recently this technique has been imported into the health service to assess aspects of service provision, ranging from service in community pharmacies $^{1}$ to the operation of telephone triage services. ${ }^{2}$ In these cases mystery shoppers are employed to use the service pretending to be patients; they are usually given a scenario to act out and told which specific aspects of the service they are to assess. Because mystery shopping relies on an element of deception in that the shopper has to ensure that those serving him or her are unaware of his or her real purpose, questions have been raised about its ethical acceptability. ${ }^{1,3}$ Here, we want to consider those ethical issues as they relate specifically to the use of mystery shoppers in the evaluation of psychiatric services, although some of the issues we raise may also apply more widely across the health service.

\section{Mystery shoppers in psychiatric services}

To make clear the ethical issues that are raised, let us look at a real-life vignette of how mystery shopping can be used in psychiatry. One could, for example, test the effectiveness and quality of care provided by a drug treatment service by employing mystery shoppers to approach the service pretending to have a problem with drug misuse. They could then carry out their evaluation of the service as they proceed as patients through their assessments by the doctor and other relevant professionals. This whole process may involve several episodes, each of which may last for some time. At the end of the whole process the pretend patients would then report back on their experience of the service.
These reports could then be used, along with other forms of evaluation, to plan improvements to, or implement changes in, the drug treatment service.

The use of mystery shoppers in this scenario involves extensive pretence and the shopper must act the role of a patient for some considerable time. In this it is very similar to research involving pseudo-patients, such as Rosenhan's study $^{4}$ of mental health facilities in which he and his assistants faked the symptoms of schizophrenia to gain access to these facilities as patients. One response to this type of research has been to argue that the deception involved renders it morally unacceptable, ${ }^{5}$ but a strict ban on these grounds looks too strong. ${ }^{6}$ There may be valuable knowledge to be gained from deceptive research. For this reason, although deceptive research would not normally be allowed, research ethics guidelines (e.g. Research Ethics Framework $^{7}$ and Statement of Ethical Practice ${ }^{8}$ ) generally allow it in some cases - yet they insist that it is only acceptable where there are no other ways to achieve the aims of the research. Furthermore, when considering whether a particular piece of deceptive research should be allowed, they stress the importance of considering two further questions: Does the deceptive method used have a good chance of achieving the ends desired? And is that end sufficiently important to justify the use of deceptive methods? Given that mystery shopping involves the same type of deception as research involving pretend patients, it seems relevant to also consider these questions in relation to it.

\section{Is deception the only way?}

It may well be that the aims of many mystery shopper programmes could not be achieved without resorting to deception. People change their behaviour when they think they are being watched, so if you want to evaluate what 
normally happens, some form of covert activity, which may well involve deception, is probably needed. ${ }^{9}$ But we still need to consider whether the mystery shopper programme itself would be able to achieve those aims. Considering the vignette outlined earlier, it is clear that for the programme to meet its aims, the mystery shoppers must be able to come across as believable patients for the duration of the interaction. This is not easy to do; it is certainly much harder than the task facing mystery shoppers in many commercial settings. In research involving people pretending to be patients it is often the case that the pseudo-patients are actually healthcare professionals as these are the people with the appropriate expertise to carry out both the deception and the assessment of the service being provided. ${ }^{10}$ Something similar would appear to be the case when using mystery shoppers to evaluate psychiatric services. Although sufficiently informed and knowledgeable people may be able to carry out the mystery shopper role in a way that helps to achieve the aim of the programme, shoppers who lack that knowledge are unlikely to do so. As such, it seems that mystery shopper programmes in psychiatric service need to be very careful about who they use as the mystery shoppers, be it healthcare professionals or service users.

\section{When does the end justify the means?}

Even if the use of mystery shoppers can achieve the aims of the programme and there is no other way to do this, there still remains a question about the importance of those aims. Considering the time a mystery shopper in our earlier vignette will take up, and the deception involved, it seems problematic to do this if the aim is something comparatively trivial. So, a question that needs to be asked about any proposal to use mystery shoppers is whether the potential gains from doing so are significant enough to justify the methods used. How this calculation turns out will depend on the details of the individual case - on what the mystery shopper programme aims to achieve and the extent of the deception involved. There is no reason to think that mystery shopping in evaluating psychiatric services will always be ruled out as the result of such an assessment. But the assessment does need to take place.

There is much to be said for this assessment to be made independently of those proposing to carry out the mystery shopper programme, as happens in the ethical evaluation of research. Given the high value placed on honesty and trust between the clinician and the patient in the health service, carrying out practices that might undermine that trust seems deeply problematic. For this reason, just as deceptive research would need to undergo independent scrutiny of its methodology and be considered by a research ethics committee, we think that a similar form of independent scrutiny should be in place for assessing the use of mystery shoppers. As the issues raised are the same, there seems no reason to accept a lower degree of scrutiny in this case than would be required were it to be framed as a research project.
Furthermore, whereas complete openness to the staff involved may defeat the aims of the programme, knowing that it has had such scrutiny is a useful way to get as much transparency into it as is possible.

What can we conclude from all this? Looking at the issues raised by research involving people pretending to be patients has highlighted areas of ethical concern that this type of deception raises, concerns that are also raised by the use of mystery shoppers to evaluate psychiatric services. As with deceptive research we do not want to say that no deception in service evaluation is ever acceptable. But there are important constraints on the ethical acceptability of such programmes. Where mystery shopping is to be used as part of service evaluation this should only occur where that evaluation cannot be done by using non-deceptive methods. It should also be ensured that the people employed as mystery shoppers are sufficiently informed and skilled, both to be able to pass effectively as patients and to carry out the appropriate evaluation. Finally, mystery shopping should only be used where independent scrutiny concludes that the importance of the aims of the evaluation is sufficient to justify the deception used.

\section{About the authors}

Tom Walker, Lecturer, Centre for Professional Ethics, Keele University. Sanju George, Consultant and Senior Research Fellow in Addiction Psychiatry, The Bridge Substance Misuse Service, Birmingham and Solihull Mental Health NHS Foundation Trust.

\section{References}

1 Jesson J. Mystery shopping demystified: is it a justifiable research method? Pharm J 2004; 272: 615-7.

2 Moriaty $H$, Mcleod D, Dowell A. Mystery shopping in health service evaluation. Br J Gen Pract 2003; 53: 942-6.

3 Levine MA. Reports of the Council on Ethical and Judicial Affairs: Secret Shopper 'Patients': 248-51. American Medical Association, 2008 (http:// www.ama-assn.org/ama1/pub/upload/mm/38/a08cejoreports.pdf).

4 Rosenhan DL. On being sane in insane places. Science 1973; 179: 250-8.

5 Newton LH. Dentists and pseudo-patients: further meditations on deception in research. IRB 1982; 4: 6-8.

6 Herrera CD. Reconsidering the pseudo-patient study. Camb Q Healthc Ethics 2001; 10: 325-32.

7 Economic and Social Research Council. ESRC Research Ethics Framework. ESRC, 2010 (http://www.esrcsocietytoday.ac.uk/ESRCInfoCentre/ Images/Framework\%20for\%20Research\%20Ethics\%202010_tcm635811.pdf).

8 British Sociological Association. Statement of Ethical Practice for the British Sociological Association. BSA, 2002 (http://www.britsoc.co.uk/ NR/rdonlyres/801B9A62-5CD3-4BC2-93E1-FF470FF10256/0/ StatementofEthicalPractice.pdf).

9 Elms AC. Keeping deception honest: justifying conditions for social scientific research stratagems. In Ethical Issues in Social Science Research (eds T Beauchamp, RR Faden, RJ Wallace Jr, L Walters): 232-45. Johns Hopkins University Press, 1982.

10 MacKay C. Reconsidering the pseudo-patient study. Commentary. Cam Q Healthc Ethics 2001; 10: 332-4. 